\title{
素质教育框架下的大学生诚信就业机制研究一以长春光华学院 为例
}

郭全

长春光华学院

DOI:10.32629/er.v3i1.2333

[摘 要] 诚信是中华民族的传统美德,当前在我们一些大学生求职就业过程中存在着不讲诚信的现象,不仅损害了大学生自身形象,也损害用人 单位的利益,损害了学校的声誉, 也不利于整个社会诚信体系的构建。面对这一现象, 如何对大学生开展诚信就业教育就成为了我们研究的一项 重要内容。

[关键词] 素质教育; 诚信教育; 养成教育; 实施方案

长春光华学院把对大学生的诚信教育纳入到养成教育当中, 并把她作 为立德树人的有利抓手, 更是素质教育的重要组成部分, 长春光华学院高 度重视学生养成教育, 把养成教育作为学校人才培养的重要目标贯彻实 施。学校从建立相关的管理制度、出台具体的实施方案、采取相关的保障 措施来强化大学生诚信教育, 从而形成学校整体的诚信就业机制。

\section{1 建立相关的管理制度}

学校于2016年按照《教育部办公厅关于进一步加强和完善高校毕业生 就业状况统计报告工作的通知》 (教学厅 (2004) 7号) 、教育部办公厅关 于做好全国普通高校未就业毕业生统计服务工作的通知 (教学厅函 (2016) 13 号) 等文件精神, 结合学校实际制定了《长春光华学院毕业生就业状况统 计管理办法》, 明确了对此项工作的组织领导、统计分类、毕业生就业状 况核查及相关工作要求。

1.1毕业生就业统计按照校、院、班三级核查的方式进行。

1. 2 明确了教育部 “四不准” 的要求。即不准以任何方式强迫毕业生 签订就业协议, 不准将毕业证书、学位证书发放与签约挂钩, 不准劝说毕业 生签订虚假协议, 不准将顶岗实习、见习证明材料作为就业证明材料。

1. 3加强对毕业生的诚信教育。要求毕业生如实申报个人就业状况, 如实回答教育部第三方调查。若发现有毕业生有不诚信行为, 将对毕业生 及相关学院进行通报。

1. 4 明确了统计工作的时间结点。6月10日前各个学院完成本院毕业生 就业状况的第一次核查, 就业指导中心依据核查结果完善数据信息报省就 业指导中心, 完成就业派遣方案数据的上报工作。8月10日前各个学院完成 本院未就业毕业生就业状况的第二次核查, 就业指导中心负责审核各院调

一定要及时转变自己的工作方式, 将信息化技术使用到档案的管理工作上 来。为了可以更好的把信息化技术融入到档案的管理工作当中, 需要建立 一个专业的档案管理系统, 并且把信息化技术运用到这个系统当中, 实现 档案的高效管理。在这个过程当中, 不仅能够保证档案信息的完整性, 还有 利于减少档案管理当中操作的时间更加方便操作, 实现高效办公。优化档 案管理的方式, 不仅仅有效缩减了档案管理工作的时间还可以提高档案管 理人员的办事效率, 对整个事业单位的管理工作都是有帮助的。

\section{4 结束语}

综上所述, 在乡镇事业单位档案的管理工作当中一定要做到严于律己, 跟进时代的发展潮流, 促进乡镇事业单位档案管理工作的质量提高。另外, 一定要从事业单位的各个部门抓起, 做好每一个部门的档案管理工作, 这 样才能方便整个事业单位工作的运行。在对乡镇事业单位的档案管理当中,
查结果上报离校未就业毕业生情况, 生成我校八月末的初次就业数据报省 高等学校毕业生就业服务中心审批。12月15日前各个学院完成对毕业生就 业状况的第三次统计, 就业指导中心依据核查结果完善数据信息上报教育 部, 完成年底就业率的上报。三次核查结果须由院长和副书记签字, 报就业 指导中心备案。

\section{2 出台相关的实施方案}

为实现我校养成教育提出的两大目标, 一是使我们的学生得实惠。二 是使我们的学校出品牌。进一步把养成教育深化、细化、做实, 长春光华 学院就业指导中心从就业工作的角度出发, 进一步探索养成教育如何与就 业工作相接轨, 养成学生的哪些好习惯将对就业工作有促进作用, 对未来 大学生的就业择业、成功成才起到关键性作用。就业指导中心针对目前大 学生群体在就业过程中缺乏责任感、责任意识淡薄的表现, 从本职工作的 角度出发制定了《长春光华学院就业工作养成教育实施方案》, 加强大学 生责任意识的培养, 构建诚信就业工作制机, 对于推动社会良性发展, 构建 和谐社会具有重要意义。

2.1 目标设计。学校把养成教育的培养目标确立为培养 “五有两能” 的应用型人才, 即胸中有志、心中有情、眼中有活儿、身上有劲儿、腹中 有才、伸手能做、张嘴能说。我们结合与就业工作相关的系列好习惯的养 成和培育, 着力把毕业生培养成学习有目标、发展有动力、职业有方向、 上岗有干劲、工作有创新的应用型人才。

2. 2 项目设计。诚信就业养成教育实施方案主要包括对大学生职业生 涯规划意识养成、就业责任意识的养成、正确择业观的养成三个部分。

2.2.1养成职业生涯规划意识。从近几年我校应届毕业生的整体情况 要根据事业单位的实际情况去制定适合自己单位的档案管理方式, 建设一 个良好的单位运行框架保障档案管理工作的质量。只有提高了档案管理工 作的水平, 才能实现乡镇事业单位档案管理的质量保障, 并且乡镇事业单 位才能平稳的发展。

\section{[参考文献]}

[1]罗濒鸣.事业单位档案管理的质量保障体系建设探析 “美丽中国” 的理解[J].现代国企研究,2018(16):105.

[2]吕峰.事业单位档案管理的质量保障体系建设探析 [J].兰台世 界,2018(04):61-62.

[3]程江余.浅谈事业单位档案管理工作的优化方法建设探析[J].才 智,2018(10):208. 
来看, 一大部分学生没有明确的职业目标, 在就业过程中, 不知道自是适合 干什么, 不知道自己想干什么, 有工作岗位招聘他也不敢尝试, 大多数学生 表现出来对就业方向的迷茫, 所以说必须要从大学一年级就得让学生有一 个清晰的职业发展思路, 树立一个明确的职业目标, 然后在四年的学习生 活中向着这个目标努力和前进。

2.2.2养成就业责任意识。我国正处在加快诚信体系建设的关键时 期, 在社会上广泛号召诚信招聘、诚信求职、诚信就业等。但是有一部 分大学生群体在求职就业中缺乏责任感, 责任意识表现不佳, 从而损害 了大学生的形象, 损害了用人单位的利益, 同进也使学校的声誉受到损 害。破坏了整个社会诚信体系的构建。因此, 我们着重强调要加强大学 生责任意识的培养, 对于构建诚信体系建设, 推动社会良性发展, 构建和 谐社会具有重要意义。

2.2.3 养成正确的择业观。我们应从实际出发, 树立大众化的就业观。 目前二三线城市急需大学生这样的高素质人才, 民营中小企业等还存在大 量的用人要求, 我们还应树立基层意识, 事业意识和奋斗意识, 到基层锻炼 自己, 掘潜能, 还可以将眼光投向西部, 西部地区锻炼成才, 步树立起“先就 业、后择业、再创业” 职业选择策略, 现实出发选择自己的求职道路。学 校组织实施毕业生基层成长计划, 服务乡村振兴战略, 引导毕业生到现代 种业、农产品加工、农村电子商务等一二三产业就业创业。继续组织实施 好 “教师特岗计划” “大学生村官” “三支一扶” “西部计划” 等中央基层 就业项目。鼓励毕业生到城乡基层从事教育文化、健康养老、扶贫开发等 工作, 到社会组织就业。

2.3 实施途径。养成负责的习惯, 做一个负责任的人。对自己负责、对 父母负责、对恋人负责、对学习负责、对工作负责。以负责的态度做每一 件事。

首先, 要针对大学生的思想状况, 及时准确地把握他们对于现实的需 求, 加以正确的引导。通过知恩感恩教育、理想信念教育、价值观教育等 活动载体, 使学生树立崇高的思想和坚定的信念, 学会为人处事, 养成对自 己负责、对他人负责。学会制定职业生涯规划, 并在行动过程中不断检验 自我的判断力和个人实行计划的效果, 不断强化责任意识。

其次, 在就业指导课程教学中, 多列举一些反面的案例, 没有责任意识 所造成的一起起惨痛矿难带给人民生命财产的重大损失, 一种种假劣食品 导致许多无幸百姓的伤害,一次次严重污染造成难以挽回的生态灾难, 一 例例触目惊心的腐败案例引发的沉重教训, 甚至一次次小小的操作失误造 成的无可挽回的损失。使学生更能直观地认识到缺乏责任意识会造成的不 良影响和严重后果。在某种程度上, 使学生认识到责任感这一道德素质在 就业过程中的重要作用, 从而规范自己的行为。
再次, 用校园文化去引领大学生负责任, 在实践中提升责任意识。第一, 要加强校风建设, 营造和谐勤勉、开拓争先的校园环境, 一切为学生的健康 成长服务。第二, 要加强师德建设, 要做一个好教师, 除了有学问, 还需要有 相应的职业道行行德和责任意识, 需要对学生的热爱和负责。第三, 要加强 学风建设。创造惜时笃学, 志存高远的氛围, 通过开展养成教育、好习惯认 领、自觉养成、主题教育、演讲、辩论、学生品德互评等活动, 引导学生 勤奋学习、乐于实践、勇于负责。

最后, 进一步做细毕业生就业指导工作, 把毕业生的责任意识放在 首位。在毕业生就业指导过程中, 要强化就业观教育和法律意识的教育, 指出大学生在签订就业协议中应承担的法律责任和因违约而导致的系 列后果。要结合学生自身的实际情况帮助他们完善个人求职材料, 把最 真实的一面反馈给用人单位, 对于存在虚假的信息, 要引导学生讲究诚 信并及时更正。在填写毕业鉴定意见时, 更是要本着实事求是的原则, 根 据毕业生的日常学习、工作表现, 客观公正地填写毕业鉴定意见, 为招聘 单位提供必要的参考。

\section{3 采取相关的保障措施}

保障措施主要包括三个层面, 一是要求每个分院副书记和院长要对学 校签订本学院毕业生诚信就业情况统计承诺书; 二是明确要求各院要组织 学生填写《长春光华学院毕业生诚信就业承诺书》。以班级为单位, 每个班 级学生在诚信就业承诺书的背面签字确认, 经班级辅导员签字后报学校就 业指导中心备案; 三是要求企业和学生签订诚信实习就业承诺书。

\section{4 总结}

毕业生诚信就业机制的建立和工作措施的实施必将增强毕业生的诚 信实习就业意识, 增强企业诚信用人意识, 营造诚信就业的良好氛围, 充分 保护毕业生和用人单位的合法权益, 必将进一步促进学校毕业生实习就业 数量和质量双提升。

\section{[参考文献]}

[1]周光苑, 李庆华.大学生道德养成教育的路径探究 [J]. 黑龙江教育 (理论与实践),2018(04):30-31.

[2]罗清霞.大学生法治观念与契约精神养成教育研究[J].学校党建与 思想教育,2018(03):79-81.

[3]兰丽平,张菪.以学生为本强化职业素养的养成教育[J].教育教学论 坛,2018(08):257-258.

作者简介：

郭全(1977--),男,汉族,吉林舒兰人,在职研究生,副研究员,研究领 域: 教学与学生管理。 